\title{
GRAMMER EUROPEAN SPINE JOURNAL AWARD FOR BASIC SCIENCE AND APPLIED RESEARCH 2018/2019
}

\section{Macrophage polarization contributes to local inflammation and structural change in the multifidus muscle after intervertebral disc injury}

Gregory James $^{1} \cdot$ Kathleen A. Sluka $^{2} \cdot$ Linda Blomster $^{1} \cdot$ Leanne Hall $^{1} \cdot$ Annina B. Schmid ${ }^{1,5} \cdot$ Cindy C. Shu $^{3}$. Christopher B. Little ${ }^{3}$. James Melrose ${ }^{3,4} \cdot$ Paul W. Hodges $^{1}$

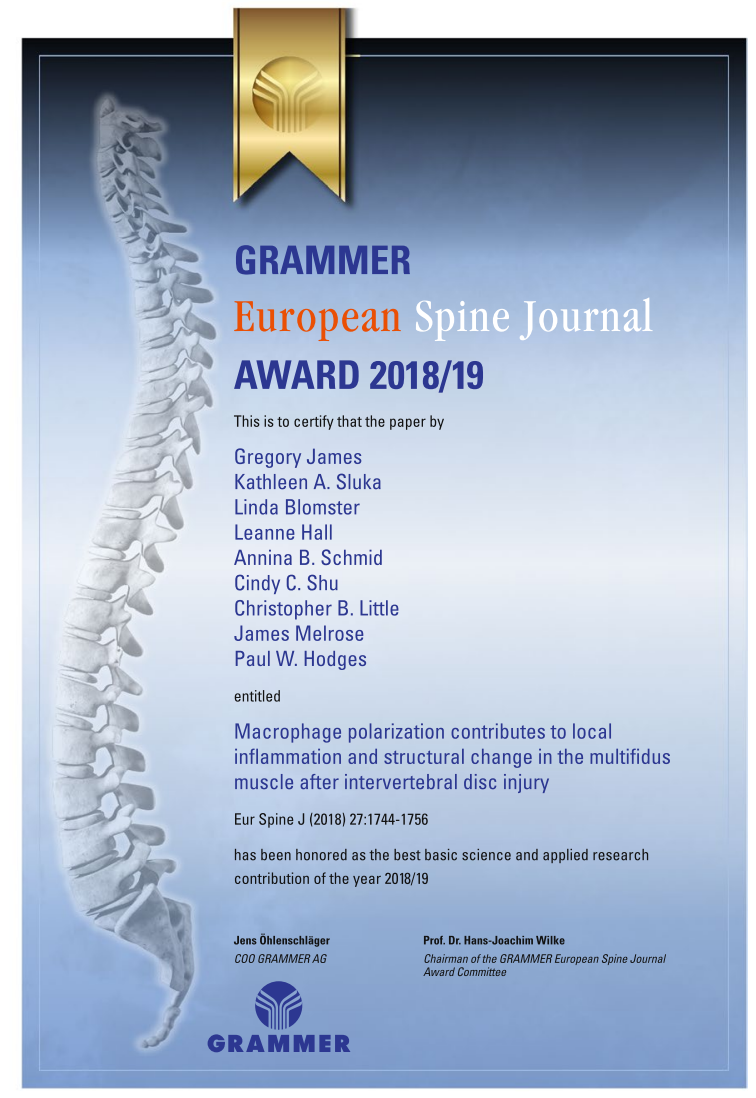

The online version of the original article can be found underhttps://doi.org/10.1007/s00586-018-5652-7. 